\title{
As Artes da Cena como conhecimento e pesquisa na escola'
}

\author{
Texto de autores convidados:
}

\author{
André Carreira ${ }^{2}$ \\ Biange Cabral ${ }^{3}$ \\ Diego de Medeiros Pereira ${ }^{4}$
}

DOI: $10.5965 / 2358092525252021006 v v V$

\begin{abstract}
1. Este material é um desenvolvimento do texto "Teatro como conhecimento" publicado por André Carreira e Biange Cabral como introdução do livro Metodologias de pesquisa em Artes Cênicas pela ABRACE, organizado conjuntamente com Luiz Fernando Ramos e Sergio Coelho Farias em 2006 pela Editora 7 Letras, Rio de Janeiro.
\end{abstract}

2. Doutor em Teatro pela Universidade de Buenos Aires. Professor do Departamento de Artes Cênicas, Programa Mestrado Profissional em Artes (Prof-Artes) e Programa de Pós-graduação em Teatro (PPGT) da Universidade do Estado de Santa Catarina (UDESC). E-mail: carreira@udesc.br.

3. Doutora em Philosophy Of Art Drama In Education pela University Of Central England. Professora aposentada do Departamento de Artes Cênicas da Universidade do Estado de Santa Catarina (UDESC). E-mail: biangecabral@hotmail.com.

4. Doutor em Teatro pela Universidade do Estado de Santa Catarina (UDESC). Professor do Departamento de Artes Cênicas, Programa Mestrado Profissional em Artes (Prof-Artes) e Programa de Pós-graduação em Teatro (PPGT) dessa instituição. E-mail: diego.pereira@udesc.br. 


\section{RESUMO}

Este texto apresenta reflexões sobre metodologia de pesquisa em artes cênicas, a partir da perspectiva da prática artística como objeto de pesquisa. Discute-se a investigação científica em artes cênicas, particularmente considerando possíveis diálogos com trabalhos desenvolvidos no espaço da escola.

Palavras-chave: prática criativa como pesquisa, arte efêmera, teatro na escola.

\section{ABSTRACT}

This text presents reflections on research methodology in performing arts, from the perspective of artistic practice as an object of research. Scientific research in performing arts is discussed, particularly considering possible dialogues with works developed in the school space.

Keywords: creative practice as research, ephemeral art, theater at school. 


\section{NOTA DE ABERTURA}

Antes de apresentar o conteúdo deste texto, dois dos autores, André e Diego, gostariam de fazer uma homenagem a essa docente e pesquisadora destacada que é Biange Cabral. Ter colaborado com ela como colega, orientando ou estudante foi uma oportunidade única para pessoas interessadas no ensino do teatro nas escolas. Nos espaços do Departamento de Artes Cênicas da UDESC ou em processo de teatro em trânsito nos bairros de Florianópolis, em atividades de pesquisa em Exeter e Londres (Inglaterra) e nos congressos da ABRACE, foi sempre interessante, provocador e divertido estar com Biange e pensar formas de criação que rompiam com os modelos mais tradicionais do teatro relacionado com a Educação. Sabemos que muitas outras pessoas viveram experiências semelhantes, resultado da extrema generosidade que sempre marcou as iniciativas que essa comprometida professora levou adiante. Sua influência repercute em muitas salas de aula nas quais professoras e professores seguem seu exemplo de buscar os modos mais variados de integrar as Artes nos processos educacionais. 


\section{INTRODUÇÃO}

A pesquisa sobre práticas artísticas e/ou pedagógicas no campo das artes cênicas lida com objetos efêmeros, propostas que têm seu maior interesse no próprio acontecimento, no instante da experiência. Isso implica na dificuldade, em alguns casos, de fixar o objeto de pesquisa e, consequentemente, de buscar procedimentos que permitam abordagens mais estáveis. Essa busca pode ser uma quimera na pesquisa, mas ainda é uma questão central para as pessoas que investigam processos e procedimentos artísticos em diferentes contextos, da cena ao chão da escola.

As artes cênicas constituem um campo diverso e múltiplo que pede um olhar que reconheça sua complexidade a partir dos distintos fazeres que compõem o que definimos como teatro e dança. Quando pensamos sobre pesquisas referentes às artes da cena na escola essa complexidade se faz ainda maior e mais desafiadora, porque o objeto parece se deslocar, sobremaneira, para os territórios da prática. A reflexão sobre processos e procedimentos se torna mais relevante, uma vez que a experiência em questão constitui terreno fértil para novos saberes dimensionados a cada contexto. Isso torna ainda mais difícil a fixação desse objeto de estudo que é mutável e extremamente dinâmico.

O caráter processual de grande parte das experiências que são objeto de projetos de pesquisa e a efemeridade da prática artístico-pedagógica são fatores determinantes para entendermos os desafios dessa categoria de pesquisa. Como consequência, surge a necessidade de se encontrar aspectos que sustentem as possibilidades de leitura dessas práticas no contexto de uma pesquisa de pós-graduação. É recorrente que nos questionemos se haveria pontos mais fixos e estáveis ou se deveríamos, simplesmente, abrir mão da pretensão de qualquer durabilidade e de apreensão do acontecimento artístico? A singularidade dos processos aparecerem dúvidas sobre a documentação e, logicamente, sobre como organizar a reflexão sobre os resultados das experimentações cênicas e pedagógicas. 
O objetivo deste texto é propor algumas reflexões sobre problemas metodológicos relacionados com a pesquisa relativa às práticas cênicas, particularizando a escola como ambiente, uma vez que o foco do Prof-Artes está nos trabalhos relacionados com a Educação Básica pública. Pretendemos contribuir com processos de pesquisa na escola que considerem as práticas das artes cênicas como laboratórios nos quais se reflete sobre os processos educacionais e artísticos, compreendendo que isso permite instalar discussões sobre as linguagens do teatro e da dança.

O primeiro aspecto que nos parece interessante se refere à delimitação do objeto de pesquisa. Nesse sentido, tomamos em consideração as palavras do físico Albert Einstein, quando esse afirmou que "a formulação de um problema é bem mais essencial do que sua solução [...] e que o estudo de antigos problemas baseados em novos pontos de vista, requer uma imaginação fértil e traz real progresso para a ciência" (1967, p. 34). O argumento do famoso cientista nos ajuda a pensar que a identificação de questões sobre nossas práticas é o ponto de partida fundamental para nossos processos de pesquisa. O que devemos tratar de formular com precisão, em primeiro lugar, é a pergunta que mobiliza a reflexão.

Formular o problema sem a urgência de uma solução imediata concreta seria a ação que poria em discussão os saberes que temos consolidados como úteis e funcionais. A formulação do problema é mais importante que sua solução porque é o que modifica o conhecimento e coloca em crise nossas formas de fazer as coisas, e impulsiona o trabalho coletivo. As soluções finalmente poderão ser diversas e complementares. A pergunta é o que produz o movimento dos processos criativos. Pensamos que a pesquisa em artes cênicas pode ser compreendida, principalmente, como uma posta em marcha de processos de discussão da própria arte.

Einstein também dizia que a formulação de um problema deveria ser feita da forma mais elegante possível. Essa elegância seria nada mais do que a busca pela simplicidade ao se pensar as questões da pesquisa. Buscar perguntas simples e compre- 
ensíveis facilitaria a reflexão coletiva sobre o objeto da pesquisa. Assim, Einstein dedicou muito tempo a construir sua famosa fórmula de modo mais simples e elegante possível para explicitar a Teoria da Relatividade: $\mathrm{E}=$ MC2.

As perguntas simples que todas as pessoas envolvidas no processo de trabalho possam compartilhar ampliam as possibilidades de reflexão coletiva e impulsionam o aprofundamento das discussões ao redor do objeto de estudo. Essas perguntas devem se relacionar tanto com os aspectos temáticos do trabaIho quanto com as dimensões formais e processuais. ${ }^{5}$

Por outro lado, tratar de olhar os velhos problemas sob novas perspectivas supõe um procedimento metodológico que aceita se deslocar das certezas já consolidadas. Isso nos conduz inevitavelmente para posições mais flexíveis e criativas porque deixamos de reafirmar o estabelecido. É necessário olhar nossas práticas artístico-pedagógicas de forma a problematizá-las abrindo nosso campo de visão de modo a vermos aquilo que consideramos teatro ou dança com novas possibilidades de realização e estudo. A pesquisadora Cecily O’Neill, entretanto, afirma:

É importante evitar a tentação de se considerar somente problemas cuja respostajá conhecemos. Estas perguntas não são autênticas. Elas podem confirmar nossas ideias, mas o processo não oferecerá surpresas, nem se produzirão verdadeiros descobrimentos. Podesermaisgenuinamenteautêntico e estético, ainda que também possa ser assustador, propor um problema para o qual não existem respostas definitivas. (O'NEILL, 1996, p. 141).

\footnotetext{
5. Como diz Cabral: "A prática como pesquisa se distingue da pesquisa sobre a prática, caracterizando-se como uma investigação centrada no relacionamento professor-aluno buscando conhecimento formal em teatro. O aspecto que a melhor identifica seria então o grau de visibilidade que ela mantém do foco da pesquisa tornando evidente durante o processo as questões sendo investigadas e as distintas formas de resposta. A natureza essencialmente social desta atividade na área do teatro acentua sua dimensão ética, ideológica e política tanto quanto epistemológica. Éticas ao questionar os valores embutidos na prática sob investigação; ideológica, na medida em que a pesquisa realizada de forma coletiva prioriza, em si, a democratização do acesso e do conhecimento; política em decorrência dos princípios de autonomia e cidadania adjacentes a estes processos". (CABRAL, 2003, p. 342).
} 
Assim, nosso ponto de partida é a reivindicação de um exercício de reflexão metodológica que considere as artes cênicas na escola a partir de referenciais dos mais diversos lugares e fazeres artísticos. Sem desconsiderar a importância do elemento didático, considerar o poético e o estético como desafios para a pesquisa na escola.

Quaisquer sejam os pontos de partida da pesquisa, o horizonte leva sempre se relaciona de alguma forma a um "espetáculo", ou seja, a uma prática na qual corpos performam em relação com outros corpos e, portanto, apresentam-se como acontecimento entre pessoas. Ainda que seja muito difícil chegar ao ponto da materialização de um espetáculo propriamente dito, e a apreensão da linguagem e o reconhecimento desta como um saber passível de ser experimentado e posto em comunicação seja um foco explícito na sala de aula, o jogo e o ensaio constituem também momentos performáticos vinculados à nossas ideias sobre o espetáculo.

As artes da cena trazem em si tantas possibilidades que aquilo que parece a delimitação de um objeto de pesquisa explícito, nada mais é que a abertura de um leque de proposições. Podemos pensar os exercícios cênicos como práticas vivas de convivência durante as quais se formulam os problemas a serem pesquisados. Entre essas práticas estão todos os formatos nos quais visualizamos experimentações de elementos das artes cênicas, dos mais simples aos mais complexos, dos jogos à cena, das investigações individuais e/ou coletivas ao espetáculo, considerando todas essas práticas com as linguagens cênicas como instâncias a partir das quais pensar a própria pesquisa.

\section{A EFEMERIDADE E A MEMÓRIA}

O teatro e a dança tentam sempre escapar das mãos ávidas de quem pesquisa, mãos que os querem segurar para caracterizá-los, destrinchá-los, descrevê-los e explicá-los. A cena parece perceber a ameaça que representa ser abordada como foco de uma pesquisa e foge para sobreviver como experiência. 
Para toda entidade dinâmica, receber nomes e ser submetida a categorizações pode significar uma morte iminente, e a arte sobrevivente se escorre pelas frestas que o pensamento analítico não consegue fechar. Isso é algo que assombra pesquisadoras e pesquisadores que estudam as artes cênicas. Uma vez fotografada ou gravada em vídeo a cena, aquela que vimos, fotografamos e gravamos, já não mais existe. Os modos de registro são apoios importantes e inestimáveis, mas não são a própria experiência da cena compartilhada em co-presença no espaço. As formas videográficas serão outra linguagem artística com suas particularidades. Esse seria o caso, por exemplo, da videodança, que é bastante diferente do registro de apresentações de dança.

As artes cênicas são efêmeras e existem nos corpos no momento da performance, e existem nas memórias das pessoas que atuaram ou assistiram. A narrativa da experiência do fazer como audiência ou artistas - é o eco da cena, é sua continuidade viva porque é um registro do afeto. Em um paralelo com a sala de aula, podemos citar as palavras de Carmela Soares:

Uma poética do efêmero como proposta metodológica para o ensino do teatro na escola pública se constrói a partir da atitude lúdica do olhar, que no seu dinamismo capta as imagens e formas que se manifestam no momento presente e lhes atribuem um sentido teatral. Esta atitude lúdica deve ser o eixo norteador das ações pedagógicas. É ela que nos permite encontrar na escola a poesia, a teatralidade das formas. (SOARES, 2010, p. 95).

Um desafio aos pesquisadores e pesquisadoras que subtraem da sua prática em sala de aula os objetos de sua pesquisa é a materialização dessas experiências. Encontrar suportes que deem conta de, de algum modo, abarcar as experiências efêmeras, os momentos poéticos, o que ficou na memória de quem instaurou ou imergiu na proposta. 
O pesquisador Marvin Carlson (2001) diz que o teatro é uma arte assombrada por fantasmas. Não os fantasmas que supostamente voam entre as coxias e corredores de velhas salas teatrais, mas pelos fantasmas das nossas memórias que recriam aquilo que vimos e sentimos quando assistimos algum espetáculo que se projetou em nós como uma experiência, como um acontecimento que nos transformou. Esses registros corporais, em maior ou menor grau, também ocorrem quando assistimos às crianças e jovens imersos em uma proposta artística ou compartilhando com seus pares suas criações. Esses diferentes elementos são materiais de pesquisa.

Ainda as pessoas que atuam podem falar desses fantasmas com alguma facilidade, porque apesar de sua efemeridade o fazer da cena tem potência para nos habitar, como fantasmas que nos conectam uma e outra vez com a experiência de nos colocarmos frente a uma audiência, mentindo verdades como o desejo de sermos agentes da transformação.

Talvez uma meta das e dos artistas da cena seja criar fantasmas - elementos potentes de memória - que perdurem nas pessoas que assistiram às suas apresentações. Considerar essas imagens como parte constituinte do nosso objeto de estudo pode nos ajudar a buscar abordagens que ampliem nossos procedimentos de registro da pesquisa, mas que, sobretudo, potencializem nossas práticas nas escolas.

\section{POSSIBILIDADE DE ENFOQUES DE PESQUISA}

A efemeridade, característica do acontecimento cênico, sempre aparece como um problema abordado por várias correntes de pensamento dentro da pesquisa da área. É claro que existe então um desejo legítimo de se apreender o objeto de forma consistente e isso produz uma força que impulsiona a busca dos melhores instrumentos para a investigação acadêmica.

O cientificismo, entretanto, proposto por algumas correntes de pesquisa, além de tentar fazer do objeto teatro - um fenômeno volátil - algo mais consistente e durável, também 
parece querer justificar a importância de tais pesquisas lhes atribuindo valores científicos. Identificar este objeto, porém, por meio de instrumentos da ciência, muitas vezes só se sustenta como argumento político dentro das disputas simbólicas e de financiamento da pesquisa.

Apesar disso, buscar semelhanças fenomenológicas entre o acontecimento de representação e outros campos de conhecimento, teria a virtude de ampliar as fronteiras do conhecimento do teatro ao redefinir zonas de trabalho antes pouco transitadas pelos pesquisadores e pesquisadoras. Isso também pode trazer elementos que renovem nossa compreensão das práticas artísticas e pedagógicas das artes cênicas, e de sua condição de fala.

Um exemplo disso são os elementos antropológicos e sociológicos observados nas situações de representação cênica e jogo, que podem ser melhor compreendidos a partir de instrumentos científicos já experimentados em outros campos e adaptados aos objetos da cena.

A pesquisa na área das artes cênicas é uma descendente direta dos avanços teóricos do campo da literatura. Os instrumentos mais importantes que deram impulso à formalização da pesquisa teórica do teatro são provenientes dos estudos literários do século XIX, pois antes de ser tratado como uma arte da performance, o teatro foi estudado na esfera do texto escrito.

Esse fato, logicamente, não satisfez a muitas abordagens que perceberam as limitações de se estudar um objeto tão dinâmico apenas a partir de uma de suas linguagens: a literária, a mais estável de todas que conformam o teatro. Nesse sentido, é possível identificar a semiologia teatral como uma das grandes alavancas teóricas que situou os estudos teatrais no terreno de sua especificidade: a identificação do texto espetacular.

Os estudos semiológicos deram a devida importância ao discurso espetacular complementando o enfoque da sociologia do teatro; se essa última centrava sua atenção nas repercussões sociais do objeto artístico ou nos reflexos artísticos dos fenômenos sociais, a semiologia buscava o desvendar de sentidos do espetáculo sem desconhecer as inter-relações entre sociedade e espetáculo. 
A semiologia teatral, a partir dos princípios de Peirce (1978), Greimas (1973) e Saussure (1971) funcionou, no final do século $X X$, como uma das principais referências na abordagem teórica do espetáculo teatral. Roland Barthes definiu o teatro como "uma máquina cibernética em funcionamento" (2003, p. 339), estabelecendo uma referência definitiva para a abordagem do acontecimento cênico como fenômeno efêmero que requer de quem o pesquisa instrumentos que reconheçam a própria dinâmica do ato espetacular e suas leis, incluindo apresentações e ensaios.

A partir da influência da pesquisadora Anne Ubersfeld, o esforço sistemático de Patrice Pavis (1997) contribuiu para que a semiologia encontrasse uma ressonância quase cotidiana nos estudos teatrais, até que o próprio autor começou a discutir a efetividade de sua aplicação, pois observou que essa metodologia particularizava a abordagem da cena a ponto de destruir o objeto ficcional do espetáculo.

Entre outros enfoques que influenciaram a pesquisa teatral estão também aqueles que identificaram instrumentos teóricos com o fim de assentar as bases de uma ciência do teatro, por assim dizer, uma teatrologia. Desses enfoques, podemos citar a sociologia da arte que causou impacto na pesquisa teatral a partir da década de 1960. Autores de áreas do pensamento tão distintas, como Herbert Read, Pierre Francastel, Arnold Hauser e Jean Duvignaud ajudaram a estabelecer as bases para uma abordagem que valorizasse o fator social no processo de leitura da obra de arte que também teve repercussões na análise do espetáculo teatral.

As práticas analíticas baseadas na sociologia da arte impulsionaram, naquele contexto, uma considerável influência de algumas correntes do pensamento marxista nos estudos artísticos. Essa influência, no entanto, traduziu-se, em muitos casos, em uma relação de causa e efeito entre eventos sociais e a obra de arte. Um exemplo extremo, mas interessante, encontra-se no livro Da investigación sociológica al fenómeno teatral de Esther Suárez Durán publicado em Havana em 1988, no qual se afirma que: 
Tanto a arte como a ciência respondem sempre às condições históricas concretas da vida da sociedade. Estão determinadas pelo Estado e o caráter das relações de produção [...]. Isto determina a existência de uma estreita relação entre o reflexo artístico que se traduz em imagens artísticas, e o pensamento científico, que o faz em conceitos, categorias e leis. Tanto o pensamento artístico como o científico refletem o mundo objetivo e se desenvolvem com a prática social. (DURÁN, 1988, p. 17).

É evidente que essa visão é uma simplificação da complexidade das relações possíveis entre arte e sociedade, e até pode parecer anacrônico dedicar atenção a esse caso. É interessante, contudo, notar que esse tipo de pensamento é bastante comum em nosso ambiente de pesquisa.

A crítica genética, proposta pela primeira vez por Louise Hay no final dos anos 1970, é outra abordagem que contribuiu para fazer mais complexas nossas aproximações ao fenômeno da cena. Seu enfoque trata de compreender os diferentes elementos que compõem e interagem nos processos de criação, sem buscar relações de causa e efeito diretas. A investigação, nesse caso, teria seu foco no processo de criação a partir da comparação de diferentes momentos da produção artística. Assim, a obra não seria só o trabalho finalizado (editado) mas aquilo que acontece nos diferentes estágios da criação.

Essa abordagem apresenta procedimentos bastante instigantes para quem busca realizar uma pesquisa que está mais próxima ao processo de criação. Ainda que se trate de procedimentos de pesquisa que não necessariamente dizem respeito ao cotidiano dos próprios artistas, a crítica genética oferece instrumentos estimulantes para quem reconhece nos seus processos criativos a matéria de sua investigação. Por isso, ela pode ser uma importante contribuição para pesquisas realizadas nos contextos de processos criativos na escola que não priorizam de forma absoluta o resultado final como algo separado dos processos pedagógicos e de criação. 


\section{A PESQUISA E A PRÁTICA COMO CONHECIMENTO}

Como estamos nos referindo principalmente a processos de pesquisa que trabalham com a experimentação prática do espetáculo, é interessante alertar para o risco de se especificar objetivos de pesquisa associados a expectativas da identificação de resultados. O risco em questão estaria no efeito restritivo que esses podem impor ao processo artístico. $O$ jogo de realizar a experiência criativa é definitivamente o centro das práticas.

Essa perspectiva de trabalho se relaciona com o fato de que: "se o teatro pensa em possibilidades de ações que buscam a participação como seu principal material, é porque se supõe que somente a ficção não é suficiente para gerar experiências, e esta talvez não possa nem produzir processos de informação eficazes". (CARREIRA, 2017, p. 05). O desafio estaria em especificar objetivos que incorporem as habilidades necessárias à criação artística, evidenciando que uma boa forma é justamente aquela que supõe o jogo de fazer o trabalho. Esse fazer é tanto relativo ao processo de ensaios como ao das apresentações.

Também é preciso que se inclua algum grau de imprecisão que permita o movimento ou deslocamento dos conteúdos cada vez que o público entre em contato com a obra. Isso estaria relacionado com a percepção de que o teatro é um meio oblíquo e não um espelho. É essa qualidade, associada à impossibilidade de controlar o ponto de partida de quem cria, que reforça a imprevisibilidade dos significados apresentados e, além disso, seus desdobramentos como experiência (percepção) do/a observador/a.

Os significados artísticos mais profundos não seriam os mais universais, mas os mais específicos, uma vez que esses estão entrelaçados com o contexto social. O contexto do jogo ficcional, ao permitir que a realidade seja suspensa, mas permaneça presente, constituiria a força das artes cênicas como ressonância entre os dois contextos.

Perceber essa dinâmica não supõe ver uma contradição natural e irremediável entre a pesquisa e o teatro ou a dança 
como prática; mas, sim, tratar de compreender os vínculos possíveis entre o estudo científico e as operações estruturais das linguagens cênicas.

A capacidade mais aguda de quem pesquisa reside justamente na possibilidade de encontrar os pontos de contato entre ambos pólos de tensão, quando os significados produzidos pelos dois campos alcançarão maior intensidade.

As artes da cena podem ser consideradas não só como formas de arte que expressam diferentes circunstâncias da experiência humana; mas, também, como seu elemento formador. Podemos, ainda, considerá-las instrumentos de interferência na vida social e observar sua potencialidade como "fala" (BARTHES, 2003) que constitui peça chave na construção do Humano.

A produção de pesquisa na área das artes cênicas representa, pois, um esforço no sentido de redimensionar o fenômeno do espetáculo em suas mais variadas manifestações, no contexto da contemporaneidade. Isso implica a reinvenção permanente de seus significados e abre o campo de pesquisa para novos lugares do fenômeno teatral, considerado como elemento fundamental na definição dos processos de construção cultural.

Também podemos pensar que a pesquisa que reflete sobre as artes cênicas na escola deve ser parte dessas contribuições que colocam em discussão a cena da contemporaneidade. É certo que a particularidade do contexto, e seu recorte preciso, faz-nos pensar em práticas isoladas e cuja especificidade as colocaria muito distante daquilo que seria propriamente a pesquisa cênica, mas isso não deveria ser obrigatoriamente assim. As circunstâncias específicas das nossas experiências cênicas na escola não precisam nos separar de forma absoluta de abordagens que podemos definir como contemporâneas. Como afirma Cabral:

O fazer teatral contemporâneo coloca em questão o cruzamento das diversas situações, vivências, circunstâncias e oportunidades no desenvolvimento de habilidades e ampliação do conhecimento. $O$ equilíbrio entre o fazer e o apreciar, entre a formação do ator e 
do espectador é enfatizado por distintas abordagens pedagógicas. A ampliação da percepção crítica requer vivências diferenciadas. Assim, a variedade de abordagens, no percurso das experiências de teatro na escola, como canal para perceber e aceitar a diferença pode ser uma meta, além de evitar a reprodução cultural e social de um modelo específico. O risco de um modelo, no contexto do ensino de teatro na escola, é o seu gradual distanciamento do fazer teatral contemporâneo. Este risco pode se acentuar se o professor não se precaver contra a rigidez e a rotina na adesão a uma metodologia específica. (CABRAL, 2007, p. 02).

Nesse sentido, é interessante considerar a definição de contemporâneo que propõe o pensador italiano Giorgio Agambem ao afirmar que "contemporâneo é tudo aquilo que coloca em discussão o seu próprio tempo" (2009, p. 59). A pesquisa cênica na escola e a própria realização cênica nesse contexto podem enfrentar o desafio de serem contemporâneas sem nenhum pudor que nasça de sua condição escolar. Como aponta Soares:

O jogo teatral realizado em sala de aula surge com a mesma forma característica da contemporaneidade: inacabada e incompleta. Não obedece a uma noção de causalidade, mas produz imagens independentes, flashes, superposições, que um olhar atento e bem treinado pode captar. (SOARES, 2010, p. 76)

Pensar a pesquisa como parte indissociável do próprio teatro e da dança contemporânea nos obriga refletir se essa pesquisa deve reafirmar seu caráter filosófico ou científico, ou buscar uma imbricação entre ambos. Um enfoque de caráter filosófico não parece ser excludente de um olhar que se arma como o instrumental científico. Proposições que buscam encontrar razões de ordem filosófica para então discutir os processos da cena têm a qualidade de propor uma aproximação às 
artes cênicas que implicam em uma ontologia do fenômeno. Nesse sentido, reflexões de ordem filosófica criam uma forma de trabalho que propõe uma classe de compromisso vinculante, estreitando a distância entre objeto e quem pesquisa.

O que surge de forma imediata a partir dessa questão é a certeza de que a vivência da arte parece, à primeira vista, ser um elemento exclusivo do/da artista. No entanto, como afirma Marco De Marinis, no campo da cena a ideia do fazer deve ser estendida além dos limites do trabalho da atuação ou direção; 'fazer' teatro é também tomar parte no funcionamento do espetáculo como acontecimento que envolve a plateia. No caso da sala de aula, como um espectador de si e dos/as colegas, seja no jogo ou na criação cênica. Assim, devemos considerar a prática cênica algo que incorpora os dois lados do fenômeno.

A produção de conhecimento no teatro é consequência das trocas nas quais participam artistas, público e quem pesquisa as artes cênicas. Então, podemos pensá-las em sua complexidade, que é exatamente aquilo que atrai o olhar da investigação. A diversidade de possibilidades e a ideia de que o teatro e a dança são máquinas cibernéticas em funcionamento, animam esse desejo de correr atrás de algo que tanto nos escapa como seduz. 


\section{REFERÊNCIAS}

AGAMBEM, Giorgio. O que é contemporâneo e outros ensaios. Argos Editora: Chapecó, 2009.

BARTHES, Roland. Las dos críticas. Barcelona: Seix Barral, 2003.

CABRAL, Biange. A prática como pesquisa na formação do professor de teatro. In: Anais ABRACE. III Congresso de Pesquisa e Pós-Graduação em Artes Cênicas. Florianópolis: UDESC, 2003.

CABRAL, Biange. Pedagogia do Teatro e Teatro como Pedagogia. In: Anais ABRACE. IV Reunião Científica de Pesquisa e Pós-Graduação em Artes Cênicas. Rio de Janeiro: UNIRIO, 2007.

CARREIRA, André. Teatro y participación política. In: Revista Conjunto, n. 184. La Habana, 2017.

CARLSON, Marvin. The Haunted stage. Ann Arbor: University of Michigan Press, 2001.

DE MARINIS, Marco. Tener experiência en el arte - Hacia uma revisión de las relaciones teoria/práctica en el marco de la nueva teatrología. In: La puesta en escena en Latinoamérica: teoria y práctica teatral. Buenos Aires: Ed. Galerna/GETEA/CITI, 1997.

DURAN, Esther Suaréz. De la investigación sociológica al fenómeno teatral. La Habana, s/e, 1988.

DUVIGNAUD, Jean. Sociología del teatro. Buenos Aires: Fondo de Cultura Económica, 1979.

EINSTEIN, Albert; INFIELD, Leopold. Evolution of Physics. New York: Simon \& Schuster, 1967. 
GREIMAS, Algirdas. Semântica estrutural. São Paulo: Cultrix, 1973.

HAUSER, Arnold. História social da literatura e da arte. São Paulo: Martins Fontes, 1995.

O'NEILL, Cecily. Into the Labyrinth: theory and research in Drama. In: Researching Drama and Arts Education - paradigms and possibilities. Londres: Falmer Press, 1996.

PAVIS, Patrice. Que teorias para que puestas en escena. In: La puesta en escena en Latinoamérica: teoria y práctica teatral. Buenos Aires: Ed. Galerna/GETEA/CITI, 1997.

PEIRCE, Charles. Écrits sur le signe. Paris: Seuil, 1978.

READ, Herbert. Arte y alienación. Buenos Aires: Proyección, 1976.

SOARES, Carmela. Pedagogia do Jogo Teatral: uma poética do efêmero. São Paulo: Hucitec, 2010. 